\title{
Head-Direction Cells Recorded from the Postsubiculum in Freely Moving Rats. I. Description and Quantitative Analysis
}

\author{
Jeffrey S. Taube, Robert U. Muller, and James B. Ranck, Jr. \\ Department of Physiology, SUNY Health Sciences Center at Brooklyn, Brooklyn, New York 11203
}

This paper is a study of the behavioral and spatial firing correlates of neurons in the rat postsubiculum. Recordings were made from postsubicular neurons as rats moved freely throughout a cylindrical chamber, where the major cue for orientation was a white card taped to the inside wall. An automatic video/computer system monitored cell discharge while simultaneously tracking the position of $\mathbf{2}$ colored light emitting diodes (LEDs) secured to the animal's head. The animal's location was calculated from the position of one of the LEDs and head direction in the horizontal plane calculated from the relative positions of the 2 LEDs.

Approximately $26 \%$ of the cells were classified as headdirection cells because they discharged as a function of the animal's head direction in the horizontal plane, independent of the animal's behavior, location, or trunk position. For each head-direction cell, vectors drawn in the direction of maximal firing were parallel throughout the recording chamber and did not converge toward a single point. Plots of firing rate versus head direction showed that each firing-rate/headdirection function was adequately described by a triangular function. Each cell's maximum firing rate occurred at only one (the preferred) head direction; firing rates at head directions on either side of the preferred direction decreased linearly with angular deviation from the preferred direction. Results from 24 head-direction cells in 7 animals showed an equal distribution of preferred firing directions over a $360^{\circ}$ angle. The peak firing rate of head-direction cells varied from 5 to 115 spikes/sec (mean: 35). The range of head-direction angles over which discharge was elevated (directional firing range) was usually about $90^{\circ}$, with little, if any, discharge at head directions outside this range. Quantitative analysis showed the location of the animal within the cylinder had minimal effect on directional cell firing. For each head-direction cell, the preferred direction, peak firing rate, and directional firing range remained stable for days. These results identify a new cell type that signals the animal's head direction in its environment.

Several lines of evidence indicate that the hippocampus is important for the processing of spatial information (O'Keefe and Conway, 1978; O'Kcefe and Nadel, 1978). First, many pyram-

\footnotetext{
Received May 12, 1989; revised Aug. 16, 1989; accepted Aug. 17, 1989.

This research was supported by NIH grants NS 07117, NS 14497, and NS 20686.

We wish to acknowledge John L. Kubie for his helpful comments throughout the course of this research. We also thank Larry Eberle for help in designing and constructing the 2 -spot tracking system.

Correspondence should be addressed to Jeffrey S. Taube, Department of Psychobiology, University of Californid at Irvine, Irvine, CA 92717.

Copyright (C) 1990 Society for Neuroscience $0270-6474 / 90 / 100420-16 \$ 02.00 / 0$
}

idal neurons in the hippocampus of freely moving rats discharge in relation to the animal's location within the environment (O'Keefe and Dostrovsky, 1971; O'Keefe, 1976; Muller et al., 1987). These neurons are called place cells because their firing is primarily location-specific and may be independent of head direction, running speed, or other descriptions of the animal's behavioral state. Location-specific firing has also been reported for cells in the dentate gyrus (Miller and Best, 1980; Rose et al., 1983). Sccond, animals with bilatcral hippocampal lesions arc impaired in a variety of spatial problem-solving tasks, including the Morris water maze (Morris et al., 1982) and radial arm maze (Olton et al., 1979). Third, some spatial abilities have been shown to be compromised in a human patient with bilateral hippocampal damage (Corkin, 1984). In addition, human patients with Alzheimer's disease, a disease associated with neuronal loss in the hippocampal formation, show marked impairments in tests involving visual-spatial functions (De Leon et al., 1984).

Retrohippocampal areas, including the subiculum, presubiculum, postsubiculum, parasubiculum, entorhinal, and perirhinal cortices, are known to have direct or indirect connections with hippocampal regions where location-specific firing has been observed (Hjorth-Simonsen and Jeune, 1972; Swanson and Cowan, 1977; Finch and Babb, 1980; Witter and Groenewegen, 1984; Finch et al., 1986). In contrast to hippocampal neurons, very little is known about the behavioral and spatial firing correlates of neurons in retrohippocampal areas. Segal and Olds (1972) reported that many subicular units increased their rate of discharge with the onset of a tone that was paired with a food reward. However, the animals in this study were not free to move around; therefore, the spatial firing correlates could not be evaluated. Currently, the neural processes involved in the formation of location-specific firing in the hippocampus and how spatial information is processed remain unclear. Thus, it would be of interest to identify the behavioral and spatial firing correlates of neurons in retrohippocampal areas from freely moving animals.

This paper and its companion (Taube et al., 1990) describe the behavioral and spatial firing correlates of a class of neurons in the postsubiculum (Brodmann area 48 ) that have been called "head-direction cells" (Ranck, 1984). Head-direction cells are named for the fact that each cell fires rapidly only when the head of a freely moving rat points in a restricted range of angles in the horizontal plane. (For brevity, the term "directional cell" will sometimes be used as a synonym for head-direction cell.) The activity of a given cell reaches a maximum about midway through the range of "yaw" or "azimuth," at an angle that will be called the "preferred direction." The firing rate is largely independent of the animal's ongoing behavior and appears to 


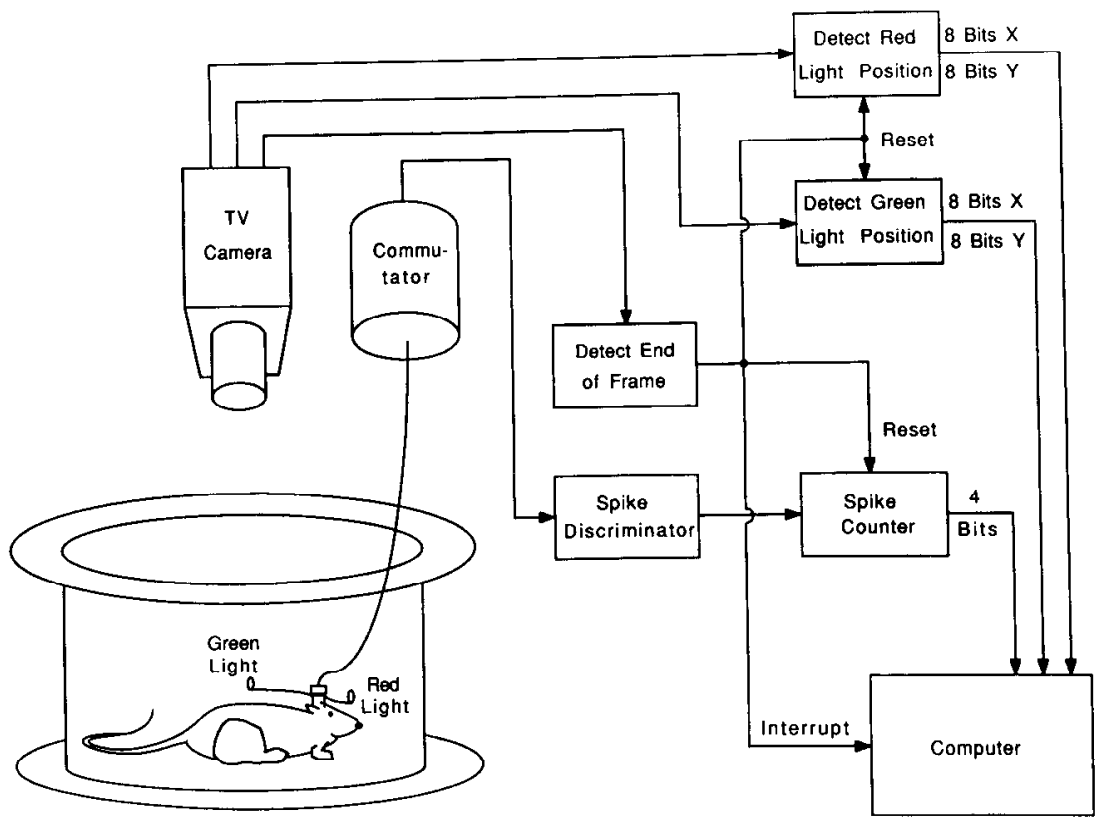

Figure 1. Block diagram showing the recording methods and apparatus. The greatly enlarged rat is shown with 2 lightemitting diodes (LEDs; 1 green, 1 red) mounted on its headstage. The red and green outputs of the vertically mounted color video camera were used to detect the positions of the LEDs, which were the brightest objects in their spectral ranges in the camera view. A clock in the camera initiated a field scan every $1 / 60$ th sec. At the start of each field, an 8-bit vertical counter and an 8-bit horizontal counter were set to zero. The vertical counter counted the number of scan lines from the field start. The horizontal counter counted pulses from the fast clock synchronized to the start of each horizontal line. When the threshold of the red channel was exceeded, the current values of the vertical and horizontal clocks were stored. The green LED position was detected in a similar way. The number of spikes fired by the cell during each $1 / 6$ th sec was also counted. At the end of each field, the digitized red and green LED positions and the spike count were sent to a computer. depend only on the angle between the midline of the head and a reference direction in the laboratory frame. A key property of head-direction cell firing is that the preferred direction is constant over the entire area of the recording chamber; thus, vectors in the direction of maximal firing are everywhere parallel. Headdirection cells therefore share with hippocampal place cells the remarkable property of signaling an aspect of the spatial relationship between the animal and its environment.

The present paper is devoted to characterizing the basic properties of head-direction cells under fixed conditions. Its main purposes are to illustrate the strength of directional-specific firing, and to quantify relationships between firing and hcad direction for individual cells and for the population. The companion paper examines changes in directional cell firing that accompany manipulations of the environment. In addition to the goal of describing head-direction cells, the present study was aimed at comparing them to place cells. For this reason, the same recording cylinder and behavioral task used by Muller et al. (1987) to study place cells were used here. Similarly, most of the environmental manipulations used to determine stimulus control for directional cell firing were similar to those used to investigate stimulus control over place cell firing (Muller and Kubie, 1987).

Preliminary reports concerning some of these findings have been presented (Ranck, 1984; Taube et al., 1987).

\section{Materials and Methods}

Most of the methods used in this study were similar to those employed by Muller et al. (1987) to record from hippocampal place cells. Accordingly, details are given here only for major departures from the earlier study.

Apparatus and behavioral training. The primary recording apparatus was a gray cylinder $76 \mathrm{~cm}$ in diameter and $51 \mathrm{~cm}$ high (Fig. 1). The cylinder was placed on a sheet of gray photographic backdrop paper that was changed before each formal recording session. The cylinder was surrounded by a brown cylindrical curtain $(216 \mathrm{~cm}$ in diameter and $216 \mathrm{~cm}$ high) that visually isolated the apparatus from the rest of the laboratory. Four uniformly spaced 25 -watt DC lights, $223 \mathrm{~cm}$ above the floor, provided illumination. A vertically oriented color video camera (Model KY-1900, JVC) was centered on the cylinder $200 \mathrm{~cm}$ above the floor. A recording cable descended from a commutator next to the camera. A sheet of white cardboard was taped inside the cylinder wall, fully occupying $100^{\circ}$ of arc, and was the only intentionally introduced asymmetry in the environment. For all experiments in this paper, this "cue card" was positioned at 3 o'clock as viewed from the overhead camera.

The purpose of the behavioral task was to have animals visit all parts of the apparatus in order to sample cell activity over the entire area. This was accomplished by training the animals to retrieve $20-\mathrm{mg}$ food pellets thrown over the curtains into the cylinder. Prior to electrode implantation, Long Evans female rats (3-4 months) were food-deprived (9-10 gm/d) and maintained on this diet for the duration of the experiment. During the first week of training, animals were handled once a day to familiarize them with the experimenter. At the start of the second week, about fifty $45-\mathrm{mg}$ food pellets were scattered on the cylinder floor and each animal was placed in the cylinder for $20 \mathrm{~min}$. At first, the animal was reluctant to move away from the cylinder wall, but after a few days it readily approached and ate food pellets away from the wall. On subsequent days, the animal was placed in the cylinder without any food, and $20-\mathrm{mg}$ food pellets were thrown into the cylinder at a rate of 3-4 pellets/min. After 1-2 weeks, the animals were demonstrably efficient at retrieving food pellets, since no pellets were left over after a training session. Training was continued until each animal spent at least $75 \%$ of its time moving around, after which electrodes were implanted.

Electrodes and surgical techniques. The recording electrode array was a movable bundle of ten $25-\mu \mathrm{m}$ nichrome wires, insulated except at the tip. The wires were threaded through a stainless steel cannula for insertion into the brain and were connected to a modified Augat connector that was in turn cemented into an acrylic base; for details on electrode construction see Kubie (1984). Animals were anesthetized with intraperitoneal pentabarbitol $(45 \mathrm{mg} / \mathrm{kg})$ and given an injection of $0.1 \mathrm{ml}$ atropine sulfate $(2.5 \mathrm{mg})$ to reduce respiratory problems. The animals were placed in a stereotaxic unit (Kopf), and electrodes implanted according to Bregma coordinates with the tips positioned just dorsal to the postsubiculum $(7.0 \mathrm{~mm}$ posterior, $3.0 \mathrm{~mm}$ right lateral from Bregma, and lowered $1.8 \mathrm{~mm}$ beneath the brain surface; Paxinos and Watson, 1986). All surgery was conducted under sterile conditions and animals were allowed to recover 4-5 d before cell screening commenced.

Screening and recording procedures. For unit screening, a 12-wire recording cable was attached to the headstage and the rat was placed in the cylinder. The headstage end of the recording cable contained 10 field effect transistor (FET) source followers, one for each electrode. The 
remaining 2 wires in the cablc werc used to power the FETs and to provide a ground via the implanted cannula. The low-output impedance signals from the FETs were sent through a commutator (Josef Biela Engineering) and then amplified (Model 7P511H, Grass Amplifier) and bandpassed-filtered ( $300 \mathrm{~Hz}$ to $30 \mathrm{kHz}, 6 \mathrm{~dB}$ /octave). The amplified signals were sent to 3 time/amplitude window discriminators (Model DIS-1, Bak Electronics) placed in series and the waveforms were displayed on an oscilloscope. Each waveform that passed through the 3 windows generated a TTL (acceptance) pulse that was sent to an audio amplifier and a spike counter.

As the animal moved around in the cylinder, each of the 10 electrodes was samplied for single-cell activity. If there were no discriminable cells, the electrode was advanced $25-50 \mu \mathrm{m}$ and the animal was returned to its home cage. Screening was conducted once or twice a day, 4-5 d/ week. When a discriminable cell was detected, its waveform and behavioral correlates were noted. If direct observation showed that the cell discharged as a function of either the animal's location or head direction, the animal was returned to its cage and the room prepared for a recording session.

Recording sessions and data acquisition. During a recording session, cell firing was recorded while the animal's head location and orientation were monitored with a video/computer 2 -spot tracker. The construction of the 2-spot tracker will be reported in a separate paper. Location and head direction were tracked by detecting a red light-emitting diode (LED) above the animal's nose and a green LED, spaced $8 \mathrm{~cm}$ back along the midline of the head (Fig. 1). The $X$ and $Y$ coordinates of each LED were determined to 1 part in 256 (16-bit resolution); with the lens used, each rectangular subregion (pixel) of the video frame was $3.6 \times$ $3.6 \mathrm{~mm}$. The LED coordinates were read into the computer (Masscomp MC5500) at $60 \mathrm{~Hz}$. In addition, the number of spikes fired during each frame was counted and sent to the computer along with the coordinate information. Since a standard recording session usually lasted $8 \mathrm{~min}$, 28,800 serial samples were gathered. Data analysis was performed offline at a later time.

Data analysis. Head direction was calculated from the relative positions of the 2 LEDs. The spatial location of the animal was defined as the position of the red LED. Given the size of an individual pixel $\left(3.6 \mathrm{~mm}^{2}\right)$ and a spacing of $8 \mathrm{~cm}$ between the red and green LEDs, the maximum resolution of head direction when the animal was in a horizontal plane was calculated to be $3.67^{\circ}$. The angular value for maximum resolution became larger (i.e., resolution became poorer) the further the animal tilted its head forward or backward. For instance, if the line between the 2 LEDs was at a $60^{\circ}$ angle to the horizontal plane (e.g., when the rat reared), the maximal resolution was reduced to $7.34^{\circ}$. Depending on the requirements, head-direction analysis was done at either 6,18 , or $45^{\circ}$ resolution. To obtain a minimal resolution of $6^{\circ}$ for head direction, the maximal angle of declination from the horizontal plane the LEDs could be was $52.3^{\circ}$.

The total time and the number of spikes discharged at each head direction during an 8-min session were summed from the collected samples. Head-direction cell firing rate as a function of head direction was determined by dividing the number of spikes in each angular bin by the time spent in each angular bin. A sample was excluded from analysis if either LED was not detected. Since most nondetects resulted from the recording cable obscuring the LEDs, a special thin recording cable was constructed that was composed of $0.28-\mathrm{mm}$-diameter wires sheathed in a black cloth tube (\#5 surgical silk; Deknatel). In addition, if the calculated distance between the 2 LEDs was $<4.89 \mathrm{~cm}$ or $>8.0$ $\mathrm{cm}$, the sample was discarded. A distance of $<4.89 \mathrm{~cm}$ occurred if the animal reared sufficiently (i.e., $>52.3^{\circ}$ ). An interlight distance $>8.0 \mathrm{~cm}$ indicated that one or both LEDs were detected erroneously since the calculated distance should not have exceeded the $8.0-\mathrm{cm}$ separation between the 2 LEDs. Such errors were nearly nonexistent.

Histology. The electrodes were usually advanced a total of about 2.5 $\mathrm{mm}$, whereupon the screening for cells was terminated. A small electrolytic lesion (Prussian blue reaction) was made on one of the wires by passing $10-20 \mu \mathrm{A}$ for $10 \mathrm{sec}$ (electrode positive). The animal was deeply anesthetized, its chest cavity opened, and a cannula inserted into the left ventrical following a $0.1-\mathrm{ml}$ injection of heparin into the heart to prevent clotting. The animal was then perfused, first with $0.9 \%$ saline followed by a $10 \%$ formalin in saline solution. The brain was removed, soaked in $10 \%$ formalin in saline for a minimum of $3 \mathrm{~d}$, and placed in a solution of $2 \%$ potassium ferrocyanide made from $10 \%$ formalin in saline for $24 \mathrm{hr}$. The brain was soaked in $10 \%$ formalin in saline for 3 more days and placed in a $30 \%$ sucrose solution until the brain sank (about $48 \mathrm{hr}$ ). The brain was then frozen, cut into $40-\mu \mathrm{m}$ sections, stained for cresyl violet, and mounted onto slides.

\section{Results}

Cell sample

A total of 239 cells were recorded from 16 animals. In all cases histological results confirmed that all recordings were from neurons in the postsubiculum. Isolated units were classified into 1 of 3 categories: (1) head-direction cells, (2) theta cells, and (3) other cells. The distinctive firing characteristics and behavioral firing correlates of head-direction cells and theta cells were easily recognized during cell screening.

Head-direction cells. Sixty-one units (25.5\%) were classified as head-direction cells, because each cell discharged rapidly only when the animal's head pointed in a particular direction relative to the laboratory frame. Head-direction cells usually had triphasic (positive-negative-positive) or biphasic (negative-positive) waveforms. The duration of the negative phase ranged from 0.2 to $0.4 \mathrm{msec}$, with bandpass filtering between $300 \mathrm{~Hz}$ and $30 \mathrm{kHz}$. The complex spikes characteristic of most hippocampal pyramidal cells (Ranck, 1973) were never seen for head-direction cells, or for any other cell type recorded from the postsubiculum. Of the 61 head-direction cells recorded, the last 25 well-discriminated cells, obtained from 7 animals, were studied with the automatic tracking system. One cell was excluded from this subsample because its tiring properties changed during 2 recording sessions. The properties of this cell will be described in detail in the next paper (Taube et al., 1990). The remaining 24 cells form the basis of the quantitative description of directional cell properties.

Theta cells. Thirty-six cells $(15.1 \%)$ were classified as theta cells (Ranck, 1973). The temporal discharge pattern of postsubicular theta cells was similar to that of hippocampal theta cells. The overall firing rate approximately doubled when the hippocampal EEG showed the theta rhythm, compared to other EEG states. During walking or running, postsubicular theta cells fired bursts of 5-8 spikes, with each burst phase-locked to the local 5- to $9-\mathrm{Hz}$ theta rhythm. The negative-going phase of the spike of postsubicular theta cells ranged from 0.2 to $0.4 \mathrm{msec}$. Although hippocampal theta cells are thought to be interneurons (Fox and Ranck, 1981), no evidence addressed the anatomical identity of postsubicular theta cells.

During monitoring of theta cell discharge, visual inspection of the animal moving around the apparatus indicated there was no correlation between theta cell firing and either head direction or the animal's location. The only distinct modulations of firing rate were associated with shifts from theta-related to non-thetarelated behaviors (Vanderwolf, 1969). The automatic tracking system was used to record 2 postsubicular theta cells. Firing rate was independent of head direction for both cells; variations around the mean rales ( 56.1 and 45.3 spikes/sec) were less than $8 \%$ in both cases. The apparent absence of directional or place correlates is in contrast to the finding that hippocampal theta cells show a place correlate (Kubie et al., 1990).

Other cells. The remaining 142 units $(59.4 \%)$ could not be classified as either head-direction or theta cells. This group of cells had a wide range of spontaneous firing rates. However, cells that had high spontaneous firing rates appeared to increase their firing during locomotion, but no other behavioral correlate was discernible. The cells with lower spontaneous firing rates had no spatial or behavioral correlates, except in a few cases. 


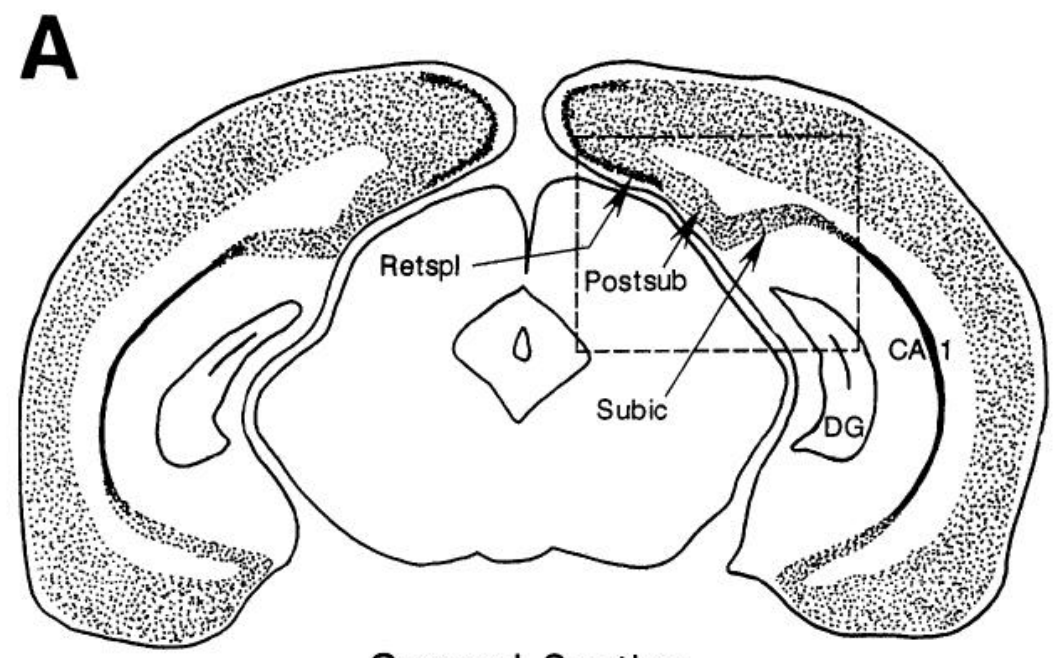

Coronal Section

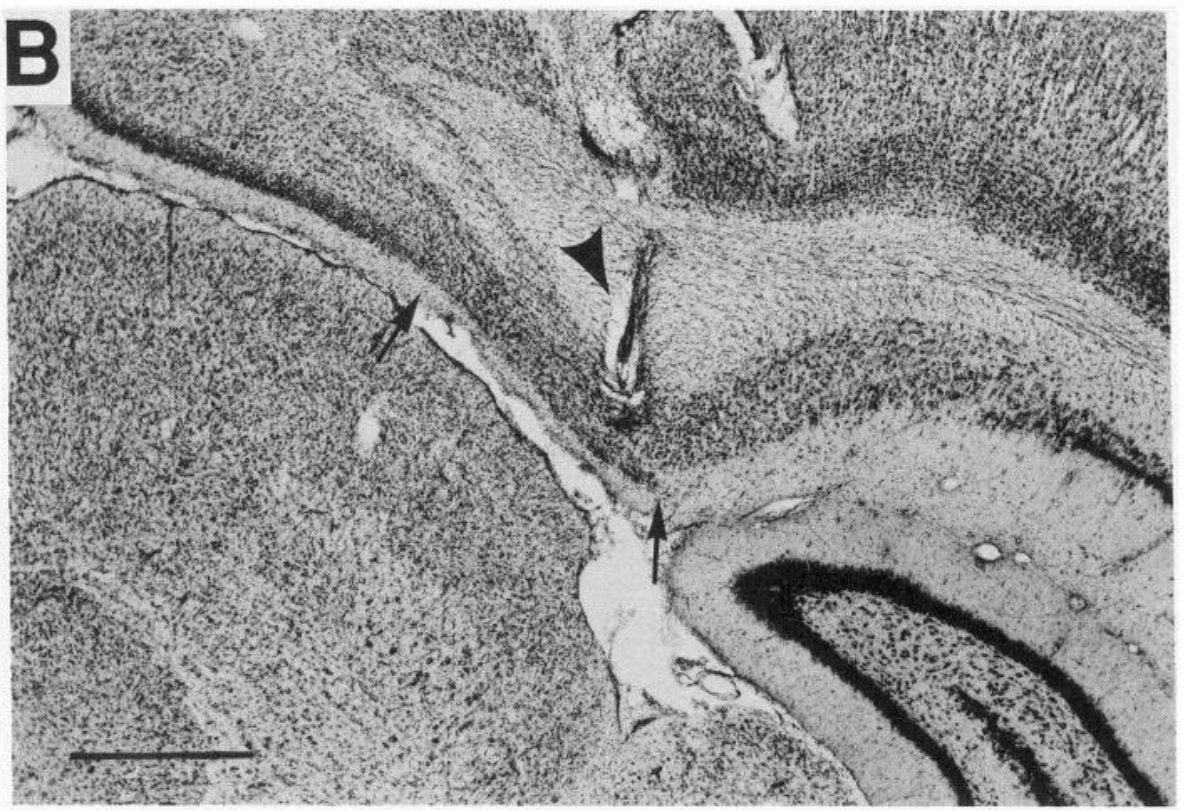

Figure 2. A, Schematic coronal section through the rat brain at the level of the postsubiculum. The dashed line indicates the area of the section from which the photo in $B$ was taken. $D G$, Dentate gyrus; $C A 1, \mathrm{CA} 1$ subfield of hippocampus; Postsub, postsubiculum; Retspl, retrosplenial cortex; Subic, subiculum. $B$, Electrode track through the postsubiculum. Arrows denote the medial and lateral boundaries of the postsubiculum. Marker shows the electrode track. Calibration bar in lower left, 1.0 $\mathrm{mm}$.
These included: (1) 1 cell whose firing was weakly but reliably modulated by head direction; (2) 2 cells whose firing was weakly modulated by the animal's location in the environment; (3) 1 cell whose firing was weakly and about equally modulated by head direction and location. Thus, except for these 3 cells whose firing was weakly correlated with location, no place cells were observed in our recordings.

\section{Histological findings}

Electrode tracks passed through the postsubiculum in all animals in which head-direction cells were encountered. An example of the position of a typical track is shown in Figure $2 B$; Figure $2 A$ locates the postsubiculum in the rat's brain.

In 4/16 animals, it was possible to get an accurate estimate of the depth at which head-direction cells were recorded. In these cases, one of the electrodes was used to make a small electrolytic lesion after the electrode array had been advanced 2.0-2.7 $\mathrm{mm}$. The animal was killed and its brain removed, sectioned, and stained with cresyl violet. Electrode tracks were identified and the distance between the electrolytic lesion and lamina dissecans (the border between layers III and IV) was measured. The depth at which head-direction cells were recorded was then calculated from the number of turns of the drive screws until the lesion was made. In these 4 animals, 32 of 35 head-direction cells were located in the deep cell layers (IV, V, and VI) of the postsubiculum; our methods are not precise enough to distinguish among the deep layers. The remaining 3 directional cells were calculated to be 90,140 , and $220 \mu \mathrm{m}$ superficial to lamina dissecans. In general, theta cells were also found in the deep layers. For 3 animals, theta cells were observed at levels deeper than head-direction cells; in 1 animal a theta cell was observed more superficially than the last recorded head-direction cell.

\section{Qualitative description of the properties of head-direction cells}

The firing rate of head-direction cells was a strong function of the head orientation in the environment. The firing rate increased from a very low background rate (usually $<1$ spike/sec) 
A

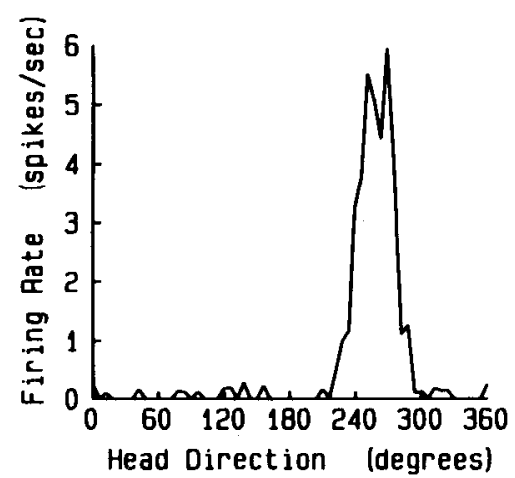

B

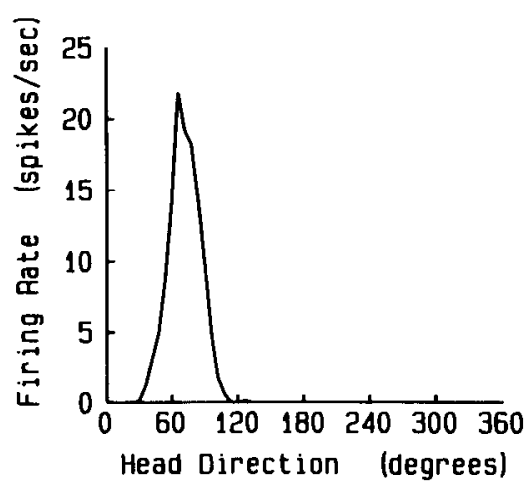

C

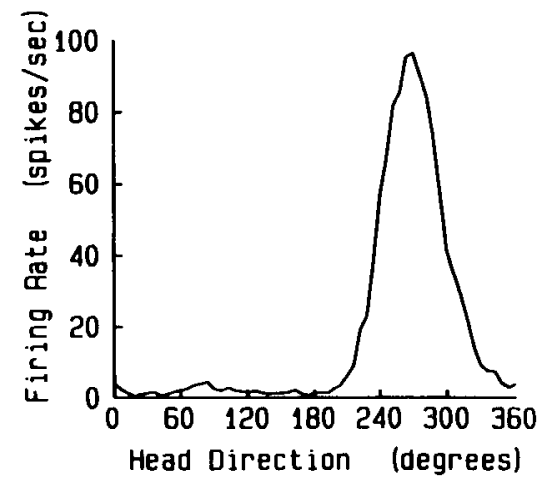

Figure 3. Firing rate as a function of head direction for 3 representative cells from 3 different animals. Each plot is based on 8 min of recording, and head direction was analyzed with a $6^{\circ}$ bin width. Note that the preferred direction and peak firing rate are different for each cell. $A$, Low-peak firing rate cell. $B$, Medium-peak firing rate cell. $C$, High-peak firing rate cell.

to a maximum rate each time the head turned either clockwise or counterclockwise to point in the preferred direction. The preferred direction for a given cell was similar over the entire area of the apparatus, so that vectors in the preferred direction were everywhere parallel and did not converge toward a single point. The firing of directional cells depended only on head direction in the horizontal plane (yaw or azimuth). When the animal was held by the experimenter, neither head pitch (pointing the nose up or down) nor roll (rotation around the anterior/ posterior axis) affected firing for rotations up to $90^{\circ}$ away from the horizontal. Only head direction appeared to be important; the position of the animal's trunk was not a firing determinant. In particular, maximal firing was observed with neck movements that turned the head to the preferred direction, or as the head orientation passed through the preferred direction when the animal moved in a curved path. Examination of the preferred directions from all directional cells recorded revealed no trend for preferred directions to cluster around a particular head direction.

The firing of head-direction cells was independent of the animal's ongoing behavior by direct observation. The firing of a head-dircction ccll was maximal at the preferred direction and was unaffected by whether the animal was eating, grooming, rearing, walking, running, or motionless; no observations were made during sleep. In addition, when the animal was carried around by hand in the cylinder or within the curtained area, the preferred firing direction was the same as when the animal moved unrestrained in the cylinder.

Although head-direction cells discharged rapidly only when the head was near the preferred direction, variations in the characteristics of the spike train were sometimes observed. The firing rate of most cells appeared to change smoothly as the head direction changed. At a constant head direction, the firing rate of these units appeared constant. In addition, the maximal firing rate was similar each time the preferred direction was attained. No adaptation of firing rate was noted when the head remained fixed at the preferred direction. In contrast to the regular and consistent firing pattern of most cells, a few directional cells were observed that discharged a burst of spikes (5-20) as the head direction passed through the preferred direction, while on other occasions they discharged only 1 or 2 spikes. Visual observations showed that this firing variation was not due to the amount of time the head pointed in the preferred direction (adaptation). Two of these cells are included in the subsample studied with the automatic tracking system. In addition, 2 other head-direction cells had unusual discharge characteristics, in that they discharged at higher firing rates as the head turned either clockwise or counterclockwise toward the preferred direction.

\section{Quantitative analysis of head-direction cells}

The directional firing specificity of head-direction cells is illustrated in Figure 3, which shows firing rate as a function of head direction for 3 typical units, recorded from 3 different animals. Each unit has a single head direction where the firing rate reaches a maximum, although the magnitude of the peak firing rate is different for each unit. In addition, the firing rate of each cell is near zero unless the animal's head points in an $\sim 90^{\circ}$ range, within which the firing rate rises to a sharp maximum. The 3 examples in Figure 3 were chosen to illustrate the fact that firingrate/head-direction functions of individual units vary mainly with regard to preferred direction and peak firing rate.

The decline of firing rate away from the peak appeared linear with either clockwise or counterclockwise head rotations away from the preferred dircction. For this rcason, wc chose to treat firing-rate/head-direction functions as triangles. Another reason for using a triangular model is that the two known sources of error would be expected to produce the accelerated widening of the rate-direction functions near the zero-rate baseline ("tails") and the rounding near the peak (most evident in Fig. $3 C$; also see Figs. 1 and 4 in Taube et al., 1990). The first error is caused by the need to categorize directional firing into angular bins of finite width. Due to averaging within the bin in which the apex of the triangle falls, the observed peak rate must be lower than the apex of the triangle. Similarly, after averaging in the bins where the triangle reaches the baseline, the observed firing rate will be higher than the height of the triangle at the midpoint of the bin. In contrast, points that lie along the sides of the triangle will be unaffected by averaging within bins because the value of the midpoint of the bin should be the same as the averaged value of the bin. Another source of error which may have caused the triangular rate-direction function to have tails and a reduced peak are the small side-to-side oscillations of the green LED as the animal moved around in the cylinder. Oscillations of the green LED would decrease the action potential count associated with the preferred direction and increase the action potential count associated with the extremes of the firing range (i.e., tails). 


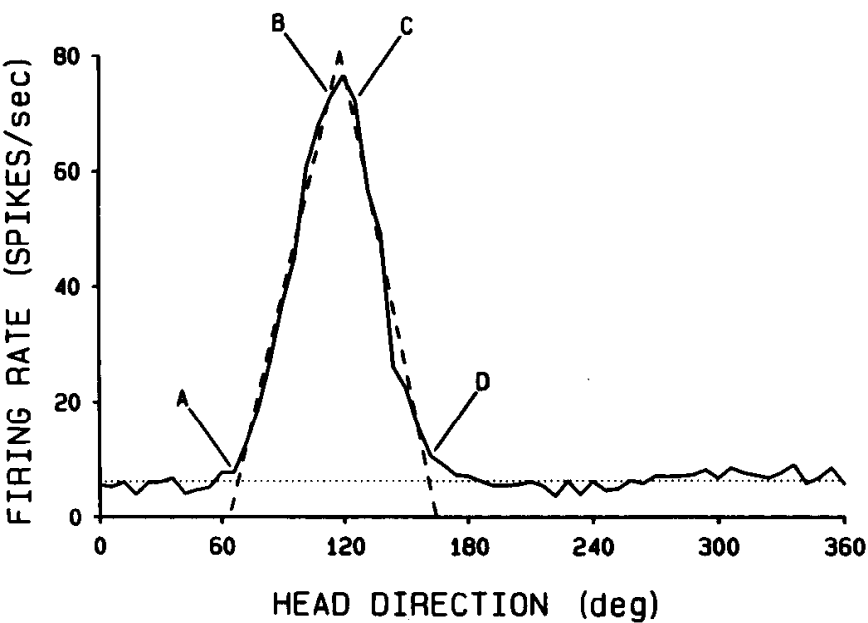

Figure 4. Summary of the triangular model of head-direction cell firing. The solid curve shows firing rate as a function of head direction for a typical head-direction cell. The 2 dashed lines, along with the base, form the triangle that was considered to best fit the raw data. The angle below the apex of the triangle is taken to be the preferred direction $\left(118.5^{\circ}\right)$. The peak firing rate is taken as the height of the triangle $(80.2$ spikes/sec). The directional firing range extends from the $X$ intercept of the left leg. of the triangle $\left(63.5^{\circ}\right)$ to the $X$ intercept of the right leg of the triangle $\left(164.6^{\circ}\right)$ and is $101.1^{\circ}$. The left leg of the triangle was obtained from a least-squares fit of the 9 data points between and including points $A$ and $B$. The right leg of the triangle was obtained from a least-squares fit of the 7 data points between and including points $C$ and $D$. The magnitude of the background firing rate $(6.26 \mathrm{AP} / \mathrm{sec})$ is indicated by the horizontal dotted line. The background firing rate was taken as the mean firing rate for all data points more than $18^{\circ}$ counterclockwise from the $X$ intercept of the left leg of the triangle and more than $18^{\circ}$ clockwise from the $X$ intercept of the right leg of the triangle (in this case, 39 points). The asymmetry of the triangle was defined as the absolute value of the left leg slope divided by the right leg slope.

Details of the triangular model are shown in Figure 4. On each side of the peak firing rate, 2 points were selected by eye to be the endpoints of a range over which to make a linear leastsquares fit. In Figure 4, points between and including $A$ and $B$ determine the left leg of the triangle, and points between and including $C$ and $D$ determine the right leg. This model was used on all cells, including those whose firing-rate/head-direction plots had 2 peaks within the elevated range of firing (e.g., Figs. $3 A$ and 13). Parameters of interest that can be derived from the model include: (1) the background (direction-independent) firing rate, defined as the mean firing rate in the head direction range between 3 bins $\left(18^{\circ}\right)$ counterclockwise to the $X$ intercept of the left leg and 3 bins clockwise to the $X$ intercept of the right leg (about 40 bins); (2) the peak firing rate, defined as the $Y$ coordinate of the apex of the triangle; (3) the preferred direction, defined as the $X$ coordinate of the apex of the triangle; (4) the width of the angular range of elevated firing, defined as the positive difference (in degrees) between the $X$ intercepts of the right and left legs of the triangle (this value will be referred to as the directional firing range); and (5) the asymmetry of the firing-rate/head-direction function, defined as the absolute value of the ratio slope of the left leg to slope of the right lcg.

The estimates of peak firing rate and width of the directional firing range could be improved, in principle, by taking the direction-independent (background noise) firing rate into account. This correction would have little effect, however, owing to the strength of the directional signal; the lowest peak to background firing rate ratio was 10.18 , suggesting that the largest correction

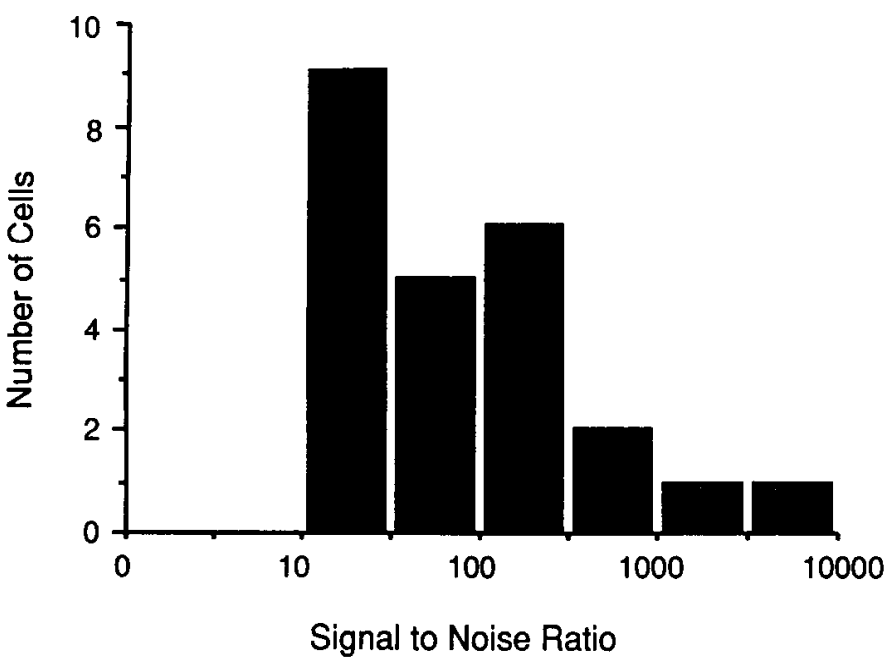

Figure 5. Histogram of the signal-to-noise ratio of head-direction cell firing. The signal is defined to be the observed peak firing rate. Note that the $X$ axis is plotted on a logarithmic scale.

would be about $10 \%$. The highest signal-to-noise ratio was 7299.7 , and the geometric mean was 83.1. Figure 5 shows the distribution of peak-to-background firing rate ratios (signal-tonoise) on a logarithmic scale.

\section{Numerical characterization of head-direction cell properties}

Background firing rates. In general, background activity was low for most units; $17 / 24$ units had a mean background firing rate of $<1.0 \mathrm{spike} / \mathrm{sec}$. The mean background firing rate was 0.91 spike/sec (range: $0.003-6.26$ spikes/sec). It was our impression that background (azimuth-independent) firing was attributable to 2 independent noise sources, and we suggest that the true background firing of directional cells is close to zero. First, mechanical recording artifacts generated when the red LED hit the cylinder wall were sometimes accepted as action potentials. Second, the amount of azimuth-independent activity seemed to be inversely correlated with the degree to which the waveform of the target cell was isolated; very well-isolated head-direction cclls showed little background activity, whereas low-amplitude units appeared to have more direction-independent activity. Over all cells, the background rate was only weakly correlated with the peak firing rate $(r=0.19)$.

Peak firing rates. The observed mean peak firing rate was 35.68 spikes/sec (range: $5.94-115.3$ spikes/sec). Figure $6 A$ shows the distribution of observed peak firing rates. High peak firing rate $(>50$ spikes/sec) and low peak firing rate $(<20$ spikes/sec) directional cells were observed within the same animal, and no trend was noted for high- or low-rate cells to occur preferentially in individual animals. Although the need to use tight discriminator settings for low-amplitude waveforms tended to reduce the apparent peak firing rate, low peak firing rates were also observed for well-isolated units. Thus, the wide range of peak firing rates appears to be a real property of the head-direction cell population.

Figure $6 B$ shows the distribution of peak firing rates derived from the triangular model. The mean peak firing rate using the triangular model was 39.62 spikes/sec (range: $6.97-130.3$ spikes/ sec) and was found to be consistently higher than the observed peak rate (paired $t=4.55 ; d f=23 ; p \ll 0.001$ ), as expected from the bin-width errors and the small vibrations of the green LED described above. The magnitude of the discrepancy (4 


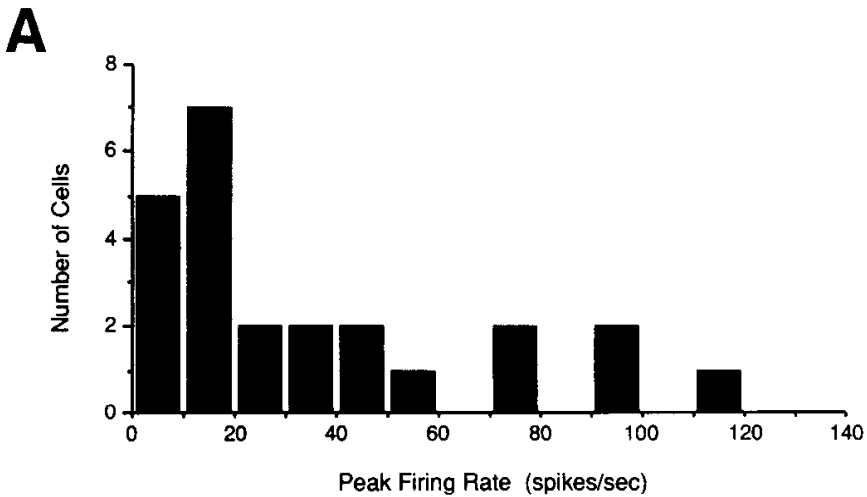

B

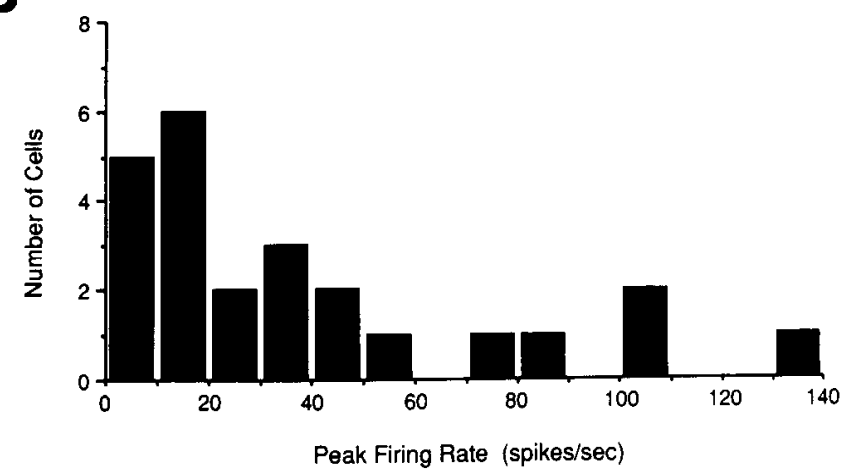

Figure 6. Histograms showing the distribution of peak firing rates for head-direction cells. $A$, Peak firing rates based on observed values. $B$, Peak firing rates rates based on observed values. $B$, Peak firing rates based on the triangular model.

spikes/sec) is not unreasonable, when taking into account the major source of error.

The error in spikes/sec due to the bin width $\left(E_{\text {bin }}\right)$ is given by:

$$
E_{\text {bin }}=(3 / 8) S W
$$

where $S$ is the mean of the absolute values of the triangle slopes (spikes $\cdot \mathrm{sec}^{-1} \cdot \mathrm{deg}^{-1}$ ) and $W$ is the width of the angular bin (deg). The mean error due to the bin width of $6^{\circ}$ was $1.97 \mathrm{spikes} / \mathrm{sec}$. If the bin error for each cell is added to the mean observed peak firing rate, the corrected mean peak firing rate is 37.5 spikes/ $\mathrm{sec}$. The residual error of $2.0 \mathrm{spikes} / \mathrm{sec}$ may have been caused in part by green LED vibration.

Distribution of preferred firing directions. The histogram of preferred firing directions revealed no trend for preferred directions to cluster around a particular head direction (Fig. 7). The low value of the Rayleigh vector $[r=0.045 ; n=24 ; p(r>$ $0.045)=0.90]$ demonstrates that preferred directions were evenly distributed around the circle. The triangular model rather consistently chose preferred directions that were rotated by small amounts counterclockwise to the observed preferred direction, taken as the head direction of the observed peak firing rate. A paired $t$-test revealed that the mean discrepancy was significantly greater than zero (mean $=1.85^{\circ} ; t=2.38 ; d f=23 ; p<$ 0.05 ). We cannot account for this observation and would not be surprised if it was not reproduced in a second cell sample.

Different head-direction cells from the same animal had different preferred firing directions, but no systematic shift in the preferred direction was observed as the electrode bundle was advanced obliquely through the deep cell layers of the postsubiculum. In 2 cases, 2 head-direction cells were recorded simul-

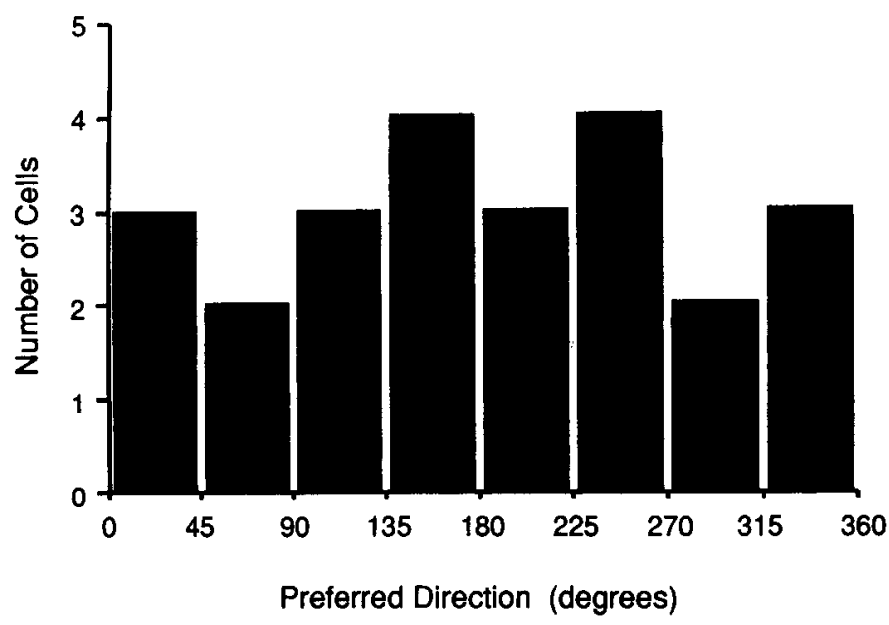

Figure 7. Histogram showing the distribution of the preferred firing direction for head-direction cells. From the histogram and the statistical analysis described in the text, there was no trend for preferred directions to occur at particular head directions.

taneously on the same electrode, but had discriminable waveforms. The differences in preferred firing directions between the 2 cells from each pair were $96^{\circ}$ and $150^{\circ}$, suggesting no trend for neighboring cells to have similar preferred firing directions.

Directional firing range. One feature of the triangular model for firing-rate/head-direction functions is that the base of the triangle is a direct estimate of the angular range of elevated firing around the preferred direction. The mean directional firing range was $83.4^{\circ}$ (range: $57.0-118.0^{\circ}$ ); the distribution of the directional firing range from the 24 head-direction cells is shown in Figure 8. The firing ranges of the 3 cells depicted in Figure 3 were 63.4, 115.9 , and $67.5^{\circ}$. Figure 9 is a scattergram of directional firing range versus peak firing rate. The correlation $(r)$ between these variables was +0.516 , indicating a weak trend for higher-firingrate cells to have wider directional firing ranges. The small amount of variance of directional firing range accounted for by peak firing rate $\left(r^{2}=0.266\right)$ implies that both values are important for characterizing the firing-rate/head-direction function for an individual cell. It is interesting to note that the angular range of elevated firing decreased smoothly into the background firing rate; no evidence was observed for an inhibitory surround.

Asymmetry of firing-rate/head-direction functions. The geometric mean of the asymmetry for the 24 head-direction cells was 1.02 (range: $0.67-1.67$ ). The asymmetries of the 3 headdirection cells illustrated in Figure 3 were $1.11,1.25$, and 0.81 . A $t$-test of the ratios did not reject the hypothesis that the mean asymmetry was $1.0(t-0.587 ; d f=23 ; p>0.5)$, suggesting that head-direction cells do not have an asymmetry in either direction. The rather wide range of asymmetry values, however, suggests that some cells may signal the direction of deviations away from the preferred direction, as well as the magnitude of the deviation.

\section{The preferred direction as a function of the animal's location}

By direct observation, it appeared that the preferred direction of a single hcad-direction cell was the same at every location in the cylinder. This observation was tested by dividing the cylinder into 12 equal area sections ( 3 annuli by 4 quadrants; see Fig. 10 A) and computing a firing-rate/head-direction function for each section. The average sampling time associated with each section was $1 / 12$ th of the total session duration. Therefore, head directions were sorted into $18^{\circ}$ bins instead of $6^{\circ}$ bins to 


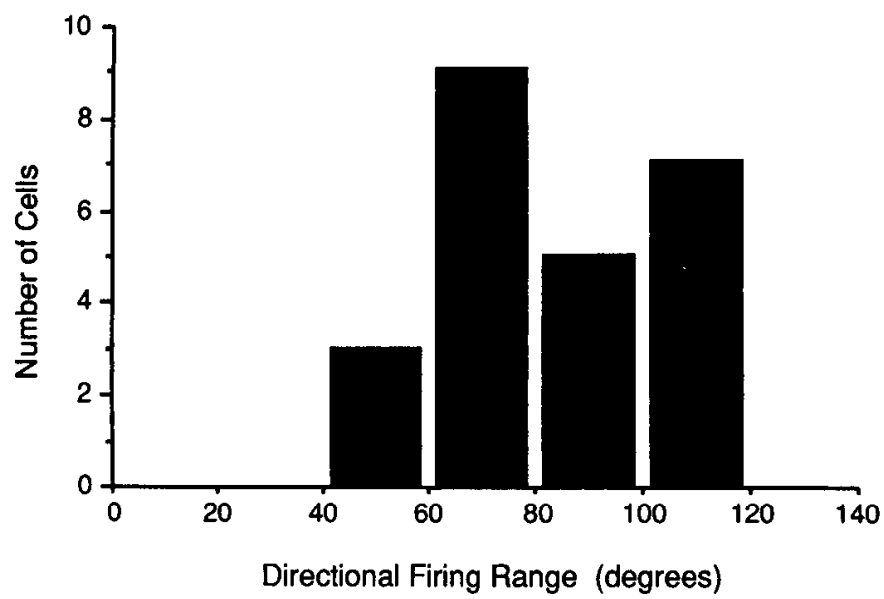

Figure 8. Histogram of the directional firing range of head-direction cells. Most cells clustered around a firing range of $90^{\circ}$.

reduce the possibility of finding location-head direction combinations that were never achieved by the animal during the session. Figure 10, $B-D$, shows superimposed sectional firingrate/head-direction plots for the 3 cells depicted in Figure 3. For these cells and the 21 others, sectional preferred directions appeared to vary only slightly from the overall preferred direction.

\section{Peak firing rate as a function of the animal's location}

The superimposed firing-rate/head-direction plots in Figure 10, $B$ and $C$, showed some variations in peak firing rate from section to section. Therefore, a more detailed analysis of peak firing rate variations in the apparatus was made by constructing headdirection-specific, color-coded maps of firing rate as a function of location (see Muller et al., 1987, for details of map construction). According to this method, the area of the cylinder was subdivided into approximately 400 square regions (pixels), 1.4 $\mathrm{cm}$ on a side. Systematic shifts in peak firing rate across the floor area of the cylinder were searched for by examining 8 maps, where each map represented the spatial firing pattern for a headdircction range of $45^{\circ}$. Three sets of direction-specific firing rate maps are shown in Figure 11. Figure $11 A$ is a map for a cell that showed little, if any, location-rate variation. Figure $11 B$ is a representative map for a cell that was judged typical of the 13 cells in which enough data (four 8-min sessions) were collected to perform the analysis. Figure $11 C$ shows a map from the only cell that was considered to have a detectable location-specific efrect.

Several features of directional cell firing in the context of the recording apparatus are visible in the maps of Figure 11. There is an "excluded" region in the cylinder that is not sampled for each head direction. This excluded region appears as a white crescent that separates the cylinder boundary (black line) from the visited region (colors). It lies symmetrically around the diametric vector that points in the selected direction for the map and is at the cylinder wall $180^{\circ}$ away from the tip of the vector. Note that the excluded region rotates around the circlc along with the head direction. The excluded region is a strictly mechanical effect that would be observed at any boundary that the animal does not cross. In the present case, in order for the head to point toward the cylinder center at the wall, the rat's body would have to stick through the wall.

The defining feature of directional cell firing is also visible in

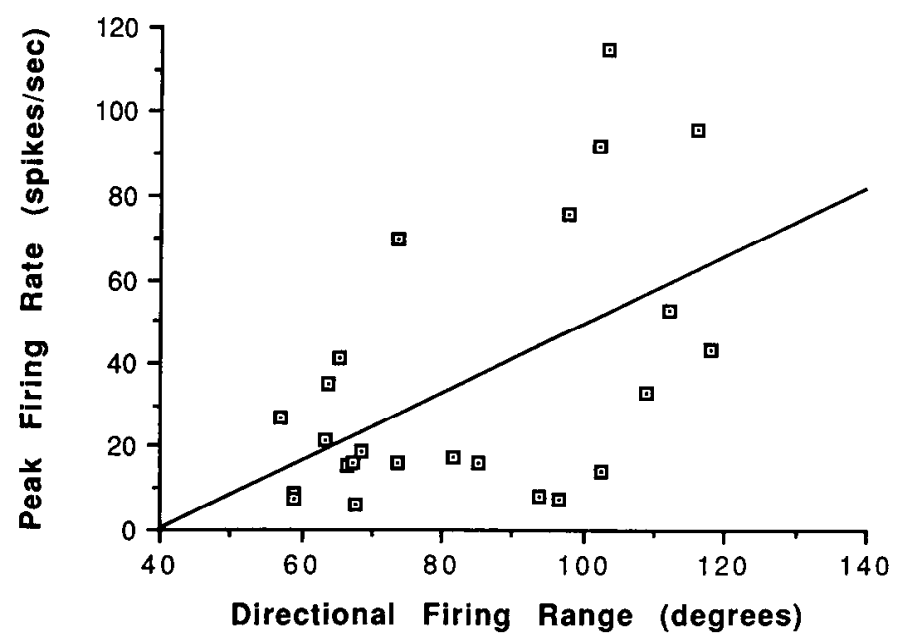

Figure 9. Scattergram of the relationship between directional firing range and peak firing rate for 24 directional cells. The solid line shows the least-squares best-fit of the data $(r=+0.516)$.

the maps of Figure 11. In the color code, yellow represents zero firing rate, whereas darker colors represent greater-than-zero rates. The high specificity of directional cell firing is readily apparent from the fact that direction-specific maps away from the preferred direction are almost entirely yellow. Furthermore, the directional specificity is high enough that the approximate angle of the preferred orientation would be evident in 2-valued rate maps, where only zero and greater-than-zero firing rates would be distinguished.

Finally, the issue of location-specific variations in firing rate while the animal's head pointed in the preferred direction must also be addressed. In the maps of Figure 11, increasing firing rates are represented in the color order orange, red, green, blue, purple. The breakpoints between the color-coded firing rate categories were selected to print approximately equal numbers of above-zero rate pixels for each color. In Figure 11A, which is for a high-peak-firing-rate directional cell, the preferred direction was in the $45^{\circ}$ bin centered on $45^{\circ}$ (Fig. 11 $A 2$ ). The purple and blue colors over the entire accessible area indicate that the firing rate did not vary as a function of location. Nearly uniform firing is observed for the angular bins on either side of $45^{\circ}$. The overall higher firing rate of the $0^{\circ}$ bin (Fig. 11AI) compared to the $90^{\circ}$ bin (Fig. 11A3) is consistent with the finding that the preferred direction was at $30^{\circ}$ and was therefore closer to the $0^{\circ}$ bin. There is a suggestion of location-specific firing-rate variation in the map for the $0^{\circ}$ firing-rate bin, where there is a region of relatively high firing near $120^{\circ}$ clock and a region of relatively low firing near 7 o'clock. We cannot explain this effect, but consider it second order and probably due to an imperfection in our methods.

Direction-specific rate maps for a medium-peak-firing-rate directional cell are shown in Figure $11 B$. For this cell, the background firing rate is extremely low. The firing rate in the $0^{\circ}$ bin (Fig. $11 B I$ ) is quite homogeneous. The origin of the elliptical low-firing-rate region at $4 \mathrm{o}^{\prime}$ clock in the $45^{\circ} \mathrm{map}$ (Fig. $11 \mathrm{~B} 2$ ) is unclear, but may be due to local undersampling. The mediumpeak-firing-rate directional cell whose activity is summarized in Figure $11 C$ was judged to fire at a higher rate when the animal was near the cylinder wall from about 7 to 11 o'clock (map \#4). Nevertheless, the direction-specific firing-rate maps show that head direction is the primary determinant of cell firing even in the case where a small location-specific effect is observed. 
A

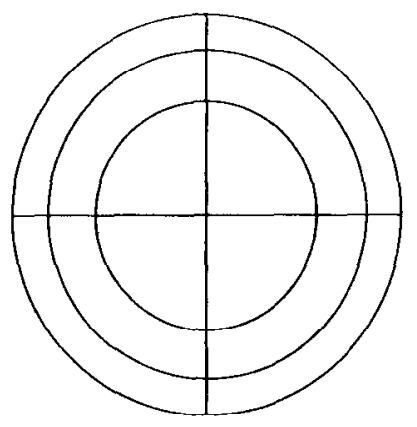

C

Figure 10. Firing rate as a function of The cylinder was divided into 12 equal area sections ( 3 annuli by 4 quadrants). The firing-rate/head-direction functions for the 12 sections are shown superimposed on each other for the 3 head-direction cells depicted in Figure 3. $B$, Low-peak-firing-rate cell. $C$, Medium-peak-firing-rate cell. $D$, Highpeak-firing-rate cell. In order to avoid undersampling, head directions were analyzed according to $18^{\circ}$ bin widths, instead of $6^{\circ}$ bin widths used in Figure 3. The results show that for each headdirection cell the rate-direction functions were similar for the 12 sections.
B

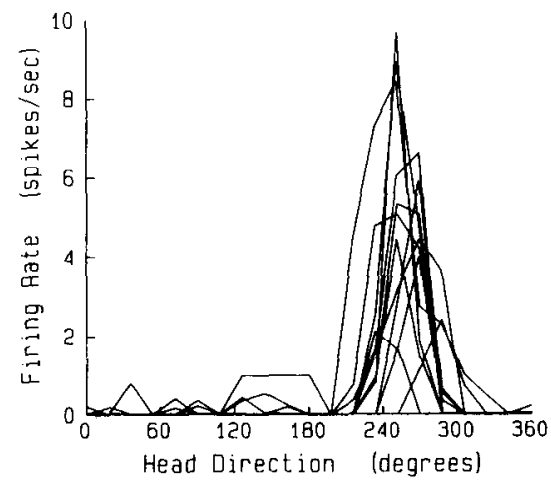

D

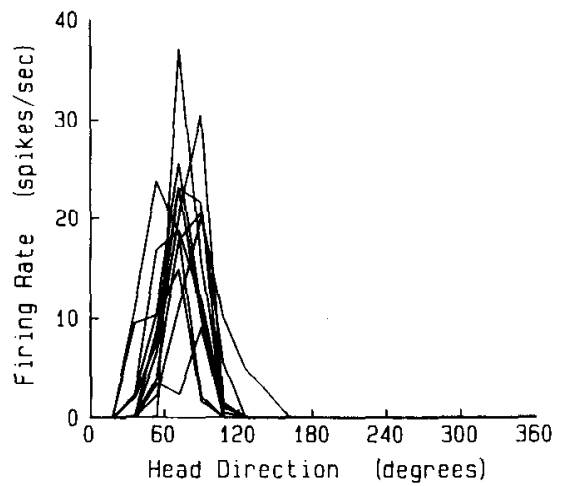

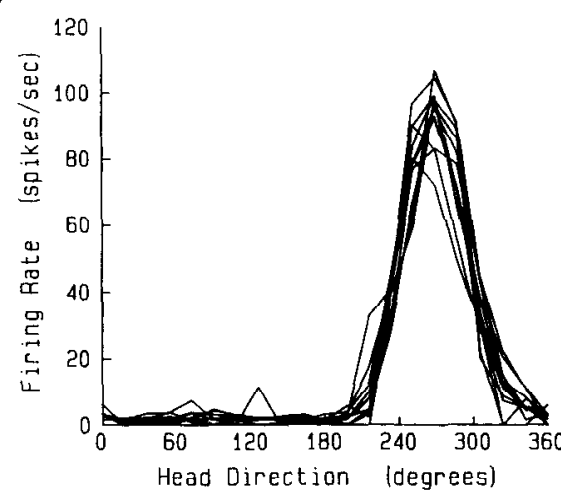

In summary, the animal's location within the cylinder weakly modulates head-direction cell activity. A more detailed treatment of this issue is warranted, however, because the directionspecific rate maps show that there are complex interactions between head direction and head location. Nevertheless, postsubicular head-direction cells show little of the location-specific firing that is characteristic of hippocampal place cells.

\section{Reliahility of head-direction cell firing}

Most directional cells appear to discharge whenever the head direction passes through the preferred direction. This obscrvation was tested by selecting from the 8 -min session all sequences of 10 consecutive samples (1/6th sec) during which the head constantly pointed in the preferred direction. The selections were made independent of whether the head moved or remained stationary during the interval. Figure $12, A$ and $B$, are histograms of preferred-direction firing rates for 2 cells whose firing was considered regular, in that they discharged similarly each time the head direction passed through the preferred direction. The histograms are representative of all except 2 cells. The remaining 2 cells showed a strong tendency to fire at high rates during some periods at the preferred direction and to have very little firing during other periods. A histogram for one of these cells is shown in Figure $12 \mathrm{C}$.

Further analysis of firing at the preferred direction indicated a trend for higher firing when the animal moved rapidly. The rat's velocity was calculated from the position of the red LED at the beginning and end of the selected sequence of constant head direction. The correlation between firing rate and velocity was then calculated for each animal. The mean correlation was 0.18 (range: -0.56 to +0.99 ); a $t$-test found that this mean value was unlikely to arise from a population with an expected value of $0.0(t=1.93 ; d f=23 ; p<0.05)$.

\section{Long-term stability of head-direction cell firing}

With the white card in the standard position, the preferred firing direction, peak firing rate, and directional firing range of indi-

Figure 11. Color-coded direction-specific firing rate maps for 3 head-direction cells. The maps set at the vertices of an octagon represent the spatial firing pattern that was observed while the animal's head pointed in the $45^{\circ}$ range centered on the arrows pointing toward each map. The map for $0^{\circ}$ (referred to as map \#1 in the text) is centered at the 3 o'clock position, with increasing degrees (and map numbers) proceeding counterclockwise around the octagon. The map in the middle is a composite firing rate map (i.e., direction-independent) that shows the overall average spatial firing pattern. The regions of low firing in the composite maps are the result of the animal's inability to put its head into that region while the head points in the preferred direction. Median firing rates for color-coded rate categories are given in the order orange, red, green, blue, purple. White pixels indicate areas that were not sampled for 4 combined 8 -min recording sessions. The firing rate for yellow-coded pixels was zero. All firing rates are in spikes/sec. A, Direction-specific maps: $1.9,15.0,51.4,85.0,111.0$. Composite map: 3.5, 10.0, 16.9, 25.7, 42.0. $B$, Direction-specific maps: $2.7,10.0,17.6,25.7,40.0$. Composite map: 0.88, 2.1, 4.1, 6.4, 11.9. C, Direction-specific maps: 3.3, 9.2, 17.1, 27.7, 45.0. Composite map: $0.65,2.1,3.9,6.2,12.9$. The firing rate maps shown in $C$ were from the only directional cell that showed a moderate locationspecific effect. 


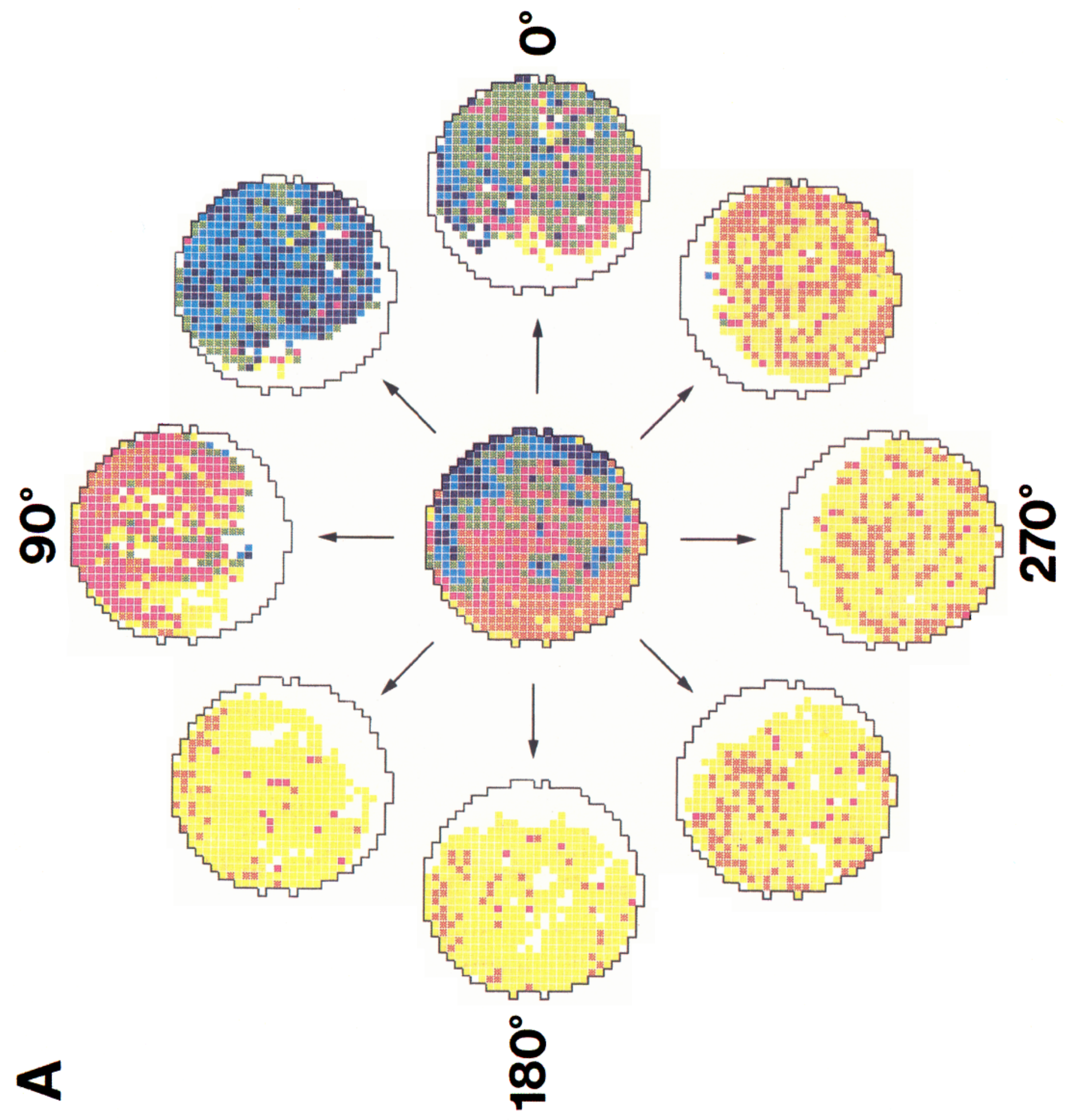




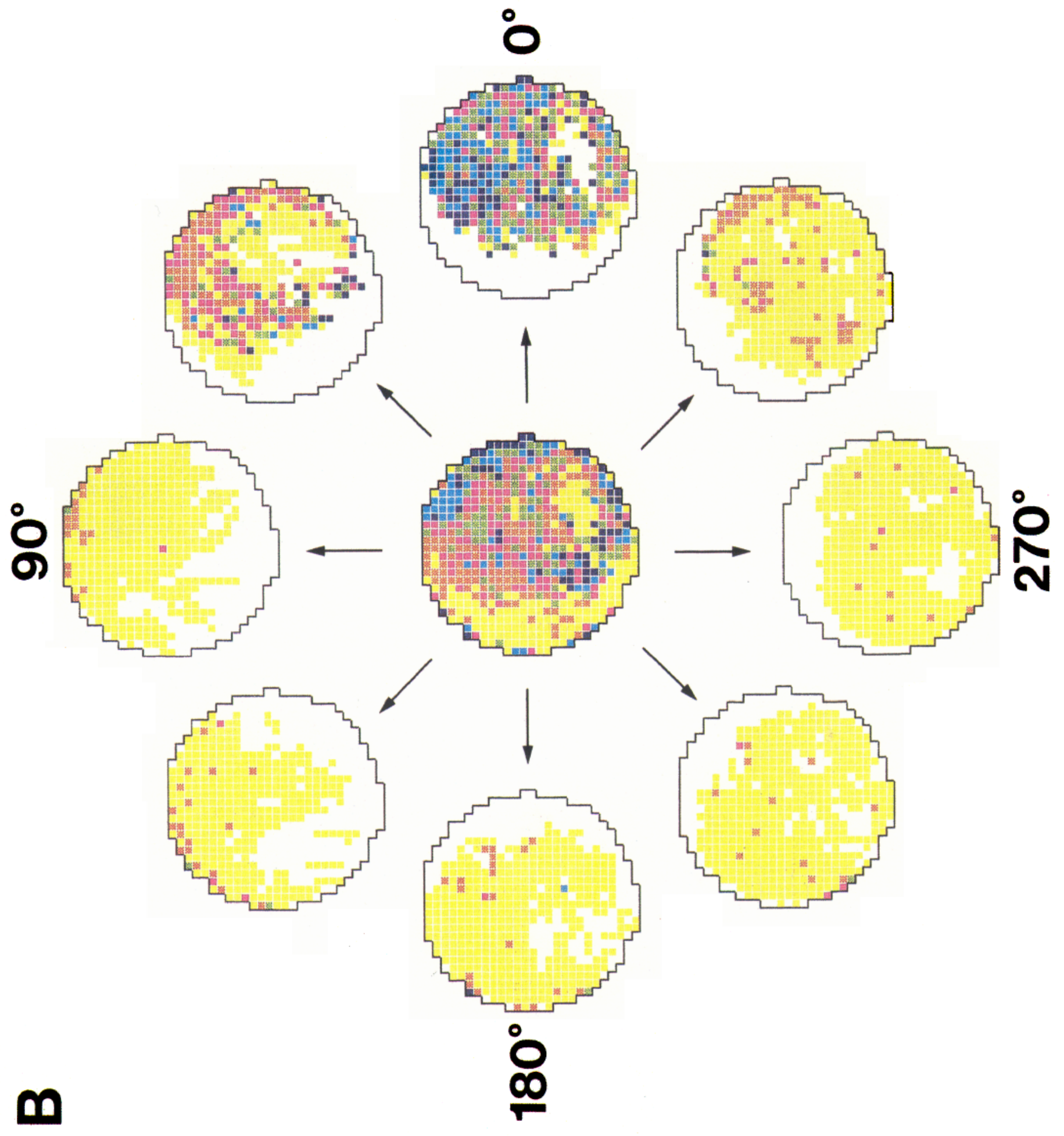




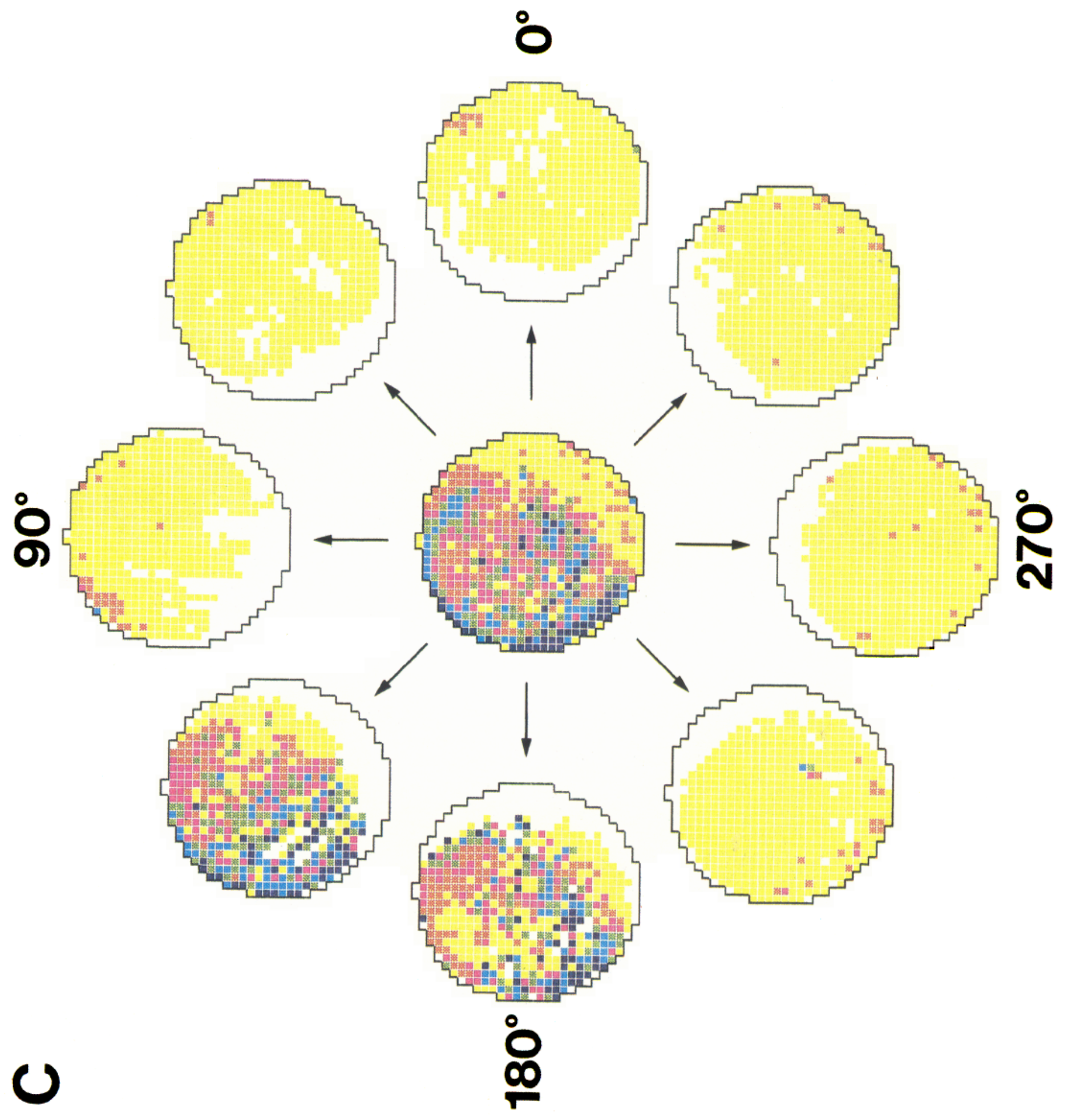




\section{A}

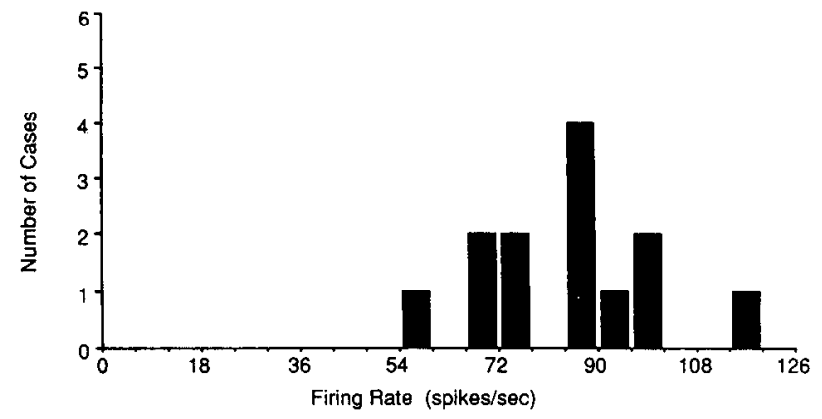

B

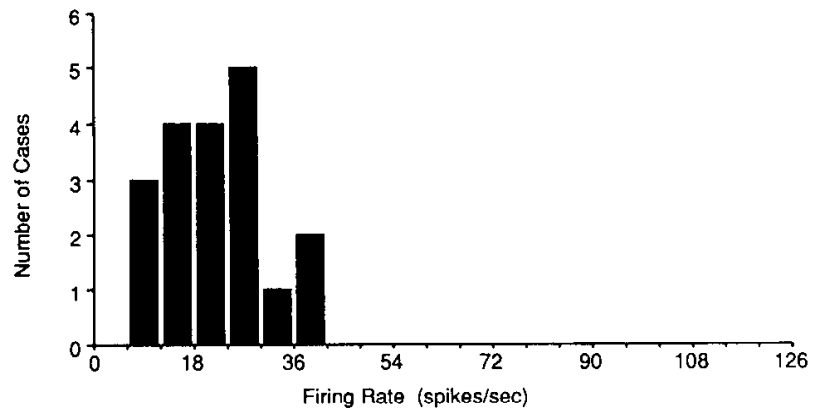

C

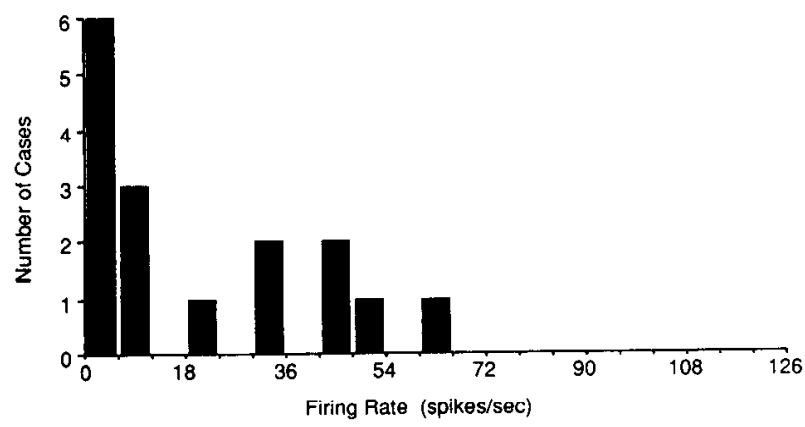

Figure 12. Histograms of the firing rates of 3 head-direction cells during $1 / 6$ th-sec episodes during which the head continuously pointed in the preferred direction. $A$ and $B$, Histograms for 2-directional cells that consistently fired whenever the head was pointed in the preferred direction. $C$, Histogram for a directional cell that fired irregularly at the preferred direction; this cell fired at high rates $(>18 \mathrm{spikes} / \mathrm{sec})$ for some periods, but discharged at very low rates $(0-6$ spikes/sec $)$ during other periods.

vidual directional cells remained stable, even when recording sessions were separated by days. Stable discharge characteristics in standard sessions were observed even when the cell was recorded under varying conditions between the 2 standard sessions (see Taube et al., 1990). At least 2 standard sessions were run on 20 cells. One cell, whose characteristics were unusual in other ways, did not show reproducibility for preferred direction and was excluded from further analysis. Properties of this cell are described in Taube et al. (1990). For the remaining 19 cells, the mean difference in preferred direction for standard session pairs was $2.5^{\circ}$ (range: -18 to $+6^{\circ}$ ). A $t$-test did not reject the hypothesis that the mean difference was $0^{\circ}(t=1.57 ; d f=18$; $p>0.05$ ).

Six head-direction cells were recorded and tested for more than $1 \mathrm{~d}$. In all cases, there was no change in firing characteristics, including the preferred direction, between different days. One unit was held for $23 \mathrm{~d}$, during which time its firing was recorded 11 times. The directional firing characteristics of this cell were

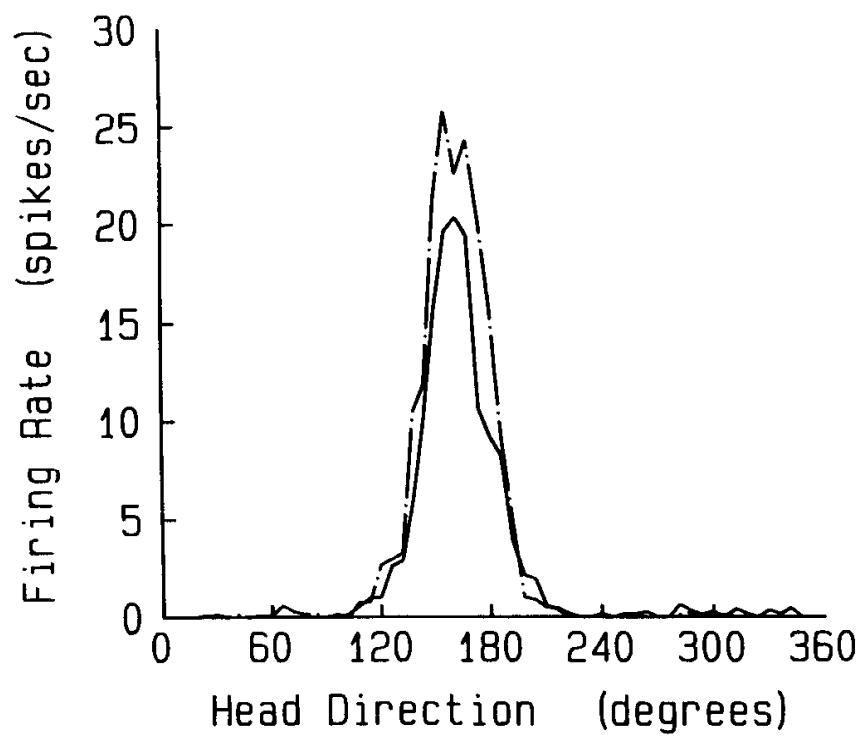

Figure 13. Stability of head-direction cell firing across time. Firingrate/head-direction functions for one head-direction cell recorded on 2 occasions $15 \mathrm{~d}$ apart. The solid line shows the results for an initial 8-min recording session, while the broken line shows the results for a second 8 -min session recorded 15 days later.

nearly constant over the entire interval, as demonstrated in Figure 13, which shows the firing-rate/head-direction functions from sessions 15 days apart.

\section{Discussion}

We have demonstrated that a class of neurons located in the deep cell layers of the postsubiculum exhibited precise directionspecific firing. Each head-direction cell fired at a maximal rate when the midline of the rat's head was pointed in a particular direction in the horizontal plane, independent of pitch or roll, body position, and the ongoing behavior while awake. In the directional cell population, all preferred directions occurred with equal frequency. The preferred direction of firing was the same over the entire area of the apparatus, so that vectors in the preferred direction were everywhere parallel. Among different head-direction cells the firing rate observed while the head points in the preferred direction varied over a wide range (5-120 spikes/ sec), whereas the angular range of elevated firing around the preferred direction was characteristically near $90^{\circ}$. It was remarkable that the firing rate of directional cells appeared to decrease linearly with head orientations away from the preferred direction. This property allowed us to characterize the firingrate/head-direction function with a triangular function. This finding must be reproduced by computational models aimed at predicting the properties of directional cells.

In this section, we first summarize what is known about the anatomy of the postsubiculum. Wc then consider the functional properties of directional cells. Finally, we discuss the sensory basis of directional cell firing in transition to the subject of the next paper.

\section{Anatomy of postsubiculum}

The postsubiculum (area 48) has been described in rats, rabbits, and cats (Brodmann, 1909; Rose and Woolsey, 1948). For the purposes of this paper and the companion paper (Taube et al., 
1990), the postsubiculum is defined as the cortical region in the dorsal half of the hippocampal formation that is lateral to retrosplenial cortex, medial to the subiculum, and dorsal to the presubiculum. This was the region from which all head-direction cells were recorded. Like all 6 layered cortex in the hippocampal formation, the postsubiculum has a distinctly cell-free lamina dissecans between layers III and IV. Almost all of the head-direction cells were found in layers deep to lamina dissecans (layers IV-VI). Both the postsubiculum and presubiculum have densely packed cells in layer II. Although the presubiculum has larger, rounder neurons in layers II and III than the postsubiculum (Vogt and Miller, 1983), this distinction is not striking. For this reason and because the reported connections of the post- and presubiculum are similar, some investigators do not recognize the postsubiculum as a distinct structure (Blackstad, 1956; Sorensen and Shipley, 1979), but rather consider it the dorsal part of the presubiculum. In this regard, it is of great interest whether head-direction cells will be found in presubicular areas that are ventral to the postsubiculum. If they are not, the case for a separate identity for the postsubiculum will be strengthened.

The connections of the postsubiculum to other brain areas are not well characterized. Previous anatomical studies concerning the postsubiculum have only been small parts of larger studies focusing on the connectivity of other regions. The exceptions are the preliminary studies of van Groen and Wyss (1988) and Wyss et al. (1988). For this reason, the summary of postsubicular connectivity that follows must be viewed as tentative and will likely be modified upon the appearance of definitive studies. In the summary, all findings are from rats, except for those stated to have come from rabbits.

The major afferent inputs to the postsubiculum are from subiculum (Sorensen and Shipley, 1979) and anterior thalamic nuclei (Niimi, 1978). van Groen and Wyss (1988) reported projections from all parts of the anterior thalamic nuclei to the superficial layers of postsubiculum. In addition, retrosplenial cortex sends fibers to layers I and III of the postsubiculum in the rat (Vogt and Miller, 1983), but to layers I and V of the postsubiculum in the rabbit (Vogt et al., 1986). Visual areas 17 and 18 have an input into postsubicular layers I and III (Vogt and Miller, 1983). Finally, the postsubiculum also receives a projection from anterior cingulate cortex (Vogt and Miller, 1983).

Major efferent projections from the postsubiculum are to layers I and III of entorhinal cortex (Swanson and Cowan, 1977) and to the anterior dorsal and anterior ventral thalamic nuclei (Swanson and Cowan, 1977; Wyss et al., 1988). The entorhinal projections from the postsubiculum originate from the superficial layers (I-III), while the deeper layers (IV-VI) project to the anterior thalamus (Donovan and Wyss, 1983). Intermediate cell layers of the postsubiculum are reported to project to the mammillary bodies (Donovan and Wyss, 1983). The postsubiculum also projects to lateral dorsal and lateral posterior thalamic nuclei (Swanson and Cowan, 1977; Wyss et al., 1988), layer I of parasubiculum (Swanson and Cowan, 1977), areas 17 and 18 (Vogt and Miller, 1983), and layer I of both cingulate and retrosplenial cortex (Swanson and Cowan, 1977; Vogt and Miller, 1983; rabbit-Vogt et al., 1986). The projection to the retrosplenial cortex originates from layer $\mathrm{V}$ of postsubiculum. Finally, it is important to note that Swanson and Cowan distinguished the postsubiculum from the presubiculum on the basis of the postsubicular projections to the retrosplenial and cingulate cortices, projections they did not find for the presubiculum.

\section{Interactions of the directional and place systems}

It is noteworthy that the efferent and afferent connections described for the postsubiculum do not include the hippocampus. Therefore, any interactions between hippocampal place cells and postsubicular head-direction cells must occur through multisynaptic pathways. One possible route for their interaction is through the subiculum, which receives hippocampal inputs from CAl and, in turn, projects to the postsubiculum. It is also possible that interactions occur in the superficial layers of entorhinal cortex, where postsubicular fibers terminate. Interestingly, it is layer II of entorhinal cortex which gives rise to the perforant path projection to the dentate, $\mathrm{CAl}$, and $\mathrm{CA} 3$ regions; all 3 are areas where location-specific firing has been observed. It should be noted, however, that the entorhinal cortex receives its inputs from the superficial layers of the postsubiculum, and not from the deep layers where head-direction cells were generally found. Preliminary single-unit recordings from entorhinal cortex have shown that many cells in layers II and III have a place correlate (Quirk and Ranck, 1986), but do not contain a clear directional signal (Quirk, personal communication).

Although it is not known how the postsubicular directional system and the hippocampal place system interact, the existence of an interaction is suggested by the presence of theta cells in the postsubiculum. The theta modulation of the activity of some postsubicular neurons is shared by cells in several limbic areas, including the medial septal nuclei and the vertical limb of the diagonal band of Broca (likely the theta pacemakers), and the entire hippocampal formation (Ranck, 1973, 1975). The presence of theta cells in CA1, CA3, and dentate regions of the hippocampus and in medial entorhinal cortex (Mitchell and Ranck, 1980) is noteworthy because these are regions in which place cells have been identified (O'Keefe and Dostrovsky, 1971; Rose et al., 1983; Quirk and Ranck, 1986; Muller et al., 1987). It may be of fundamental importance that structures concerned with the animal's spatial relationship with the environment all undergo synchronous modulations of excitability. In this context, it is interesting that theta generation in the hippocampal formation is highly correlated with locomotion by the animal (Vanderwolf, 1969). Although the ubiquity of theta cells and, more generally, the theta modulation of limbic neuronal activity is an important finding, the functional significance of the theta rhythm and its generators remains unclear.

\section{Comparison of head-direction cells and place cells}

The functional properties of head-direction cells may be compared with those of place cells observed in the hippocampus. When place cells are recorded in the same fixed environment used in the present study, their firing is almost ideally locationspecific. Place cell activity is nearly independent of all variables except the animal's location (Muller et al., 1987) and in particular is independent of head direction in the cylinder (Bostock et al., 1988). In the cylinder, therefore, the correlates of directional and place cell firing are independent, except as dictated by mechanical considerations. The firing of head-direction cells appears to be one dimensional, in the sense that it is determined by a single parameter. The firing of place cells is 2 dimensional, in the sense that it is determined by 2 parameters - the $X$ and $Y$ coordinates in the horizontal plane. It should be added, however, that place cells show an azimuth-specific firing component when recorded from rats running on an 8 -arm radial maze (McNaughton et al., 1983; Bostock et al., 1988; Leonard et al., 
1988). In contrast, there is little evidence for location-specific firing in directional cells.

Place and head-direction cells show no apparent trend for neighboring units to have some form of topographic organization of the firing fields or preferred directions. Knowing the location of the firing field of one place cell does not help predict the firing field location of a nearby place cell (O'Keefe, 1976; Muller et al., 1987). Similarly, knowing the preferred direction of a head-direction cell does not help predict the preferred direction of a nearby head-direction cell. The firing of cells in both classes is very reliable under constant conditions (cf. Muller et al., 1987), and both types of cells show very high specificity for thcir primary firing correlate.

The 2 cell types, however, differ in several important ways. First, hippocampal place cells often have more than one firing field within an environment (Muller et al., 1987). In contrast, no head-direction cell was observed with more than one range of elevated firing, even though some cells had 2 peaks within that range. Second, the range of peak firing rates observed for directional cells $(5-150$ spikes/sec) is wider than the range for place cells $(0-50 \mathrm{spikes} / \mathrm{sec})$. Third, the firing range of directional cells is consistently near $90^{\circ}$, about $25 \%$ of the range of possible values. In contrast, the fraction of the cylinder occupied by place cell firing fields is more variable, ranging between 0 and $50 \%$ of the area (Muller et al., 1987).

The characteristics of head-direction cells discussed in this paper are derived from recordings made in a fixed environment. The question of how directional cells respond to changes in the environment are addressed in the next paper (Taube et al., 1990). These experiments address the issue of sensory control over directional cell firing and permit additional comparisons with place cells, since modifications of place cell firing after the same environmental manipulations have been described previously (Muller and Kubie, 1987). Similarities and differences between the responses of the 2 cell classes to manipulations of the cue card and geometry of the apparatus are important because both cells types appear to be involved with the animal's ability to navigate in its environment.

\section{References}

Blackstad, T. W. (1956) Commissural connections of the hippocampal region in the rat, with special reference to their mode of termination. J. Comp. Neurol. 105: 417-537.

Bostock, E. M., J. S. Taube, and R. U. Muller (1988) The effects of head orientation on the firing of hippocampal place cells. Soc. Neurosci. Abstr. 14: 127.

Brodmann, K. (1909) Vergleichende Lokalisationslehre der Grosshirnrinde in ihren Prinzipien dargestellt auf Grund des Zellenbauses, J. A. Barth, Leipzig.

Corkin, S. (1984) Lasting consequences of bilateral medial temporal lobectomy: Clinical course and experimental findings in H.M. Semin. Neurol. 4: 249-259.

De Leon, M. J., M. Potegal, and B. Gurland (1984) Wandering and parietal signs in senile dementia of Alzheimer's type. Neuropsychobiology 11: 155-157.

Donovan, M. K., and J. M. Wyss (1983) Evidence for some collateralization between cortical and diencephalic efferent axons of the rat subicular cortex. Brain Res. 259: 181-192.

Finch, D. M., and T. L. Babb (1980) Neurophysiology of the caudally directed hippocampal efferent system in the rat: Projections to the subicular complex. Brain Res. 197: 11-26.

Finch, D. M., E. E. Wong, E. L. Derian, and T. L. Babb (1986) Neurophysiology of the limbic system pathways in the rat: Projection from the subicular complex and hippocampus to the entorhinal cortex. Brain Res. 397: 205-213.

Fox, S. E., and J. B. Ranck, Jr. (1981) Electrophysiological charac- teristics of hippocampal complex-spike and theta cells. Exp. Brain Res. 41: 399-410.

Hjorth-Simonsen, A., and B. Jeune (1972) Origin and termination of the hippocampal perforant path in the rat studied by silver impregnation. J. Comp. Neurol. 144: 215-232.

Kubie, J. L. (1984) A drivable bundle of microwires for collecting single-unit data from freely moving rats. Physiol. Behav. 32: 115118.

Kubie, J. L., R. U. Muller, and E. M. Bostock (1990) Spatial firing properties of hippocampal theta cells. J. Neurosci. (in press).

Leonard, B. J., B. L. McNaughton, and C. A. Barnes (1988) Locationand direction-specific discharge of rat hippocampal complex-spike cells in an open field and on the radial 8-arm maze. Soc. Neurosci. Abstr. 14: 396.

McNaughton, B. L., C. A. Barnes, and J. O'Keefe (1983) The contributions of position, direction and velocity to single unit activity in the hippocampus of freely moving rats. Exp. Brain Res. 52: 41-49.

Miller, V. M., and P. J. Best (1980) Spatial correlates of hippocampal unit activity are altered by lesions of the fornix and entorhinal cortex. Brain Res. 194: 311-323.

Mitchell, S. I., and J. B. Ranck, Jr. (1980) Generation of theta rhythm in medial entorhinal cortex of freely moving rats. Brain Res. 189: $49-66$.

Morris, R. G. M., P. Garrud, J. N. P. Rawlins, and J. O'Keefe (1982) Place navigation impaired in rats with hippocampal lesions. Nature 297: 681-683

Muller, R. U., and J. L. Kubie (1987) The effects of changes in the environment on the spatial firing of hippocampal complex-spike cells. J. Neurosci. 7: 1951-1968.

Muller, R. U., J. L. Kubie, and J. B. Ranck, Jr. (1987) Spatial firing patterns of hippocampal complex-spike cells in a fixed environment. J. Neurosci. 7: 1935-1950.

Niimi, M. (1978) Cortical projections of the anterior thalamic nuclei in the cat. Exp. Brain Res. 31: 403-416.

O'Keefe, J. (1976) Place units in the hippocampus of the freely moving rat. Exp. Neurol. 51: 78-109.

O'Keefe, J., and D. H. Conway (1978) Hippocampal place units in the freely moving rat: Why they fire where they fire. Exp. Brain Res. 31: 573-590.

O'Keefe, J., and J. Dostrovsky (1971) The hippocampus as a spatial map. Preliminary evidence from unit activity in the freely-moving rat. Brain Res. 34: 171-175.

O'Keefe, J., and L. Nadel (1978) The Hippocampus as a Cognitive Map, Clarendon, Oxford, U.K.

Olton, D. S., J. T. Becker, and G. E. Handelmann (1979) Hippocampus, space, and memory. Behav. Brain Sci. 2: 313-365.

Paxinos, G., and C. Watson (1986) The Rat Brain in Stereotaxic Coordinates, Academic, New York.

Quirk, G. J., and J. B. Ranck, Jr. (1986) Firing of single cells in entorhinal cortex is location specific and phase locked to hippocampal theta rhythm. Soc. Neurosci. Abstr. 12: 1524.

Ranck, J. B., Jr. (1973) Studies on single neurons in dorsal hippocampal formation and septum in unrestrained rats. Part I. Behavioral correlates and firing repertoires. Exp. Neurol. 41: 461-535.

Ranck, J. B., Jr. (1975) Behavioral correlates and firing repertoires of neurons in dorsal hippocampal formation and septum of unrestrained rats. In The Hippocampus Vol. 2: Neurophysiology and Behavior, R. L. Isaacson and K. H. Pribram, eds., pp. 207-244, Plenum, New York.

Ranck, J. B., Jr. (1984) Head-direction cells in the deep cell layers of dorsal presubiculum in freely moving rats. Soc. Neurosci. Abstr. 10: 599.

Rose, G., D. Diamond, and G. S. Lynch (1983) Dentate granule cells in the rat hippocampal formation have the behavioral characteristics of theta neurons. Brain Res. 266: 29-37.

Rose, J. E., and C. N. Woolsey (1948) Structure and relations of limbic cortex and anterior thalamic nuclei in rabbit and cat. J. Comp. Neurol. 89: 279-347.

Segal, M., and J. Olds (1972) Behavior of units in the hippocampal circuit of the rat during learning. J. Neurophysiol. 35: 680-690.

Sorensen, K. E., and M. T. Shipley (1979) Projections from the subiculum to the deep layers of the ipsilateral presubicular and entorhinal cortices in the guinea pig. J. Comp. Neurol. 188: 313-334.

Swanson, L. W., and W. M. Cowan (1977) An autoradiographic study of the organization of the efferent connections of the hippocampal formation in the rat. J. Comp. Neurol. 172: 49-84. 
Taube, J. S., R. U. Muller, and J. B. Ranck, Jr. (1987) A quantitative analysis of head-direction cells in the postsubiculum. Soc. Neurosci. Abstr. 13: 1332.

Taube J. S., R. U. Muller, and J. B. Ranck, Jr. (1990) Head-direction cells recorded from the postsubiculum in freely moving rats. II. Effects of environmental manipulations. J. Neurosci. 10: 436-447.

Vanderwolf, C. II. (1969) Hippocampal electrical activity and voluntary movement in the rat. Electroencephalogr. Clin. Neurophysiol. 26: $407-418$.

van Groen, T., and J. M. Wyss (1988) The distribution of projections from the anterior thalamic nuclei to the subicular cortex. Soc. Neurosci. Abstr. 14: 921.

Vogt, B. A., and M. W. Miller (1983) Cortical connections between rat cingulate cortex and visual, motor, and postsubicular cortices. J. Comp. Neurol. 216: 192-210.

Vogt, B. A., R. W. Sikes, H. A. Swadlow, and T. G. Weyand (1986) Rabbit cingulate cortex: Cytoarchitecture, physiological border with visual cortex, and afferent cortical connections of visual, motor, postsubicular, and intracingulate origin. J. Comp. Neurol. 248: 74-94.

Witter, M. P., and H. J. Groenewegen (1984) Laminar origin and septotemporal distribution of entorhinal and perirhinal projections to the hippocampus in the cat. J. Comp. Neurol. 224: 371-385.

Wyss, J. M., I. van Groen, and C. Rodenburg (1988) Topography of anterior thalamic nuclei afferents from the posterior limbic cortex and the contralateral anteroventral nucleus. Soc. Neurosci. Abstr. 14:921. 